\title{
Climate change impact assessment on Zhoshui River water supply in Taiwan
}

\author{
Jyun-Long Lee and Wen-Cheng Huang*
}

Department of Harbor and River Engineering, National Taiwan Ocean University, Keelung City, Taiwan

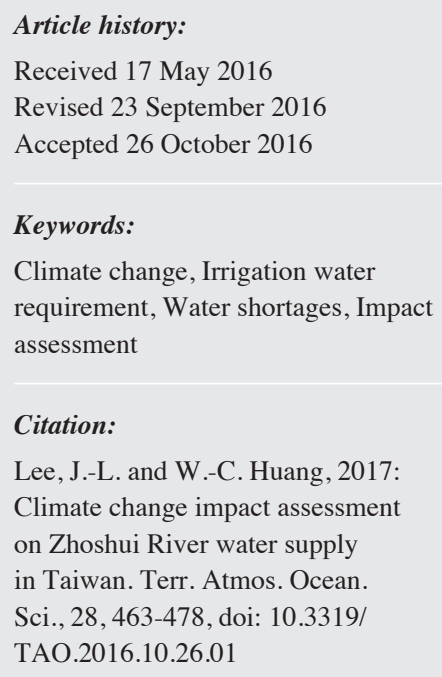

\begin{abstract}
This study evaluates the impact of climate change on water resources. An integrated procedure is proposed for assessing the water resources system response to climate change on the basin scale. The Zhoshui River basin in Central Taiwan was selected for the impact assessment. Five downscaled general circulation models based on the A1B scenario for 2046 - 2065 were adopted to assess the climate change impact, including (1) the irrigation water requirement downstream of the basin, (2) the river flow upstream of the basin, and (3) the water resources utilization related to supply and demand in the basin. Rising temperatures will cause the irrigation water requirement to increase by $10 \%$. Precipitation in the basin will substantially decrease and likely cause a $20 \%$ decrease in river flow. Thus, irrigation water shortages may become more severe in the future. As an adaptation, the Hushan Reservoir, which will begin operation in mid-2016, can assist in offsetting domestic and industrial demand. To maintain the irrigation deficit at the present level (2001 - 2010) in the future, conveyance losses should reduce to $30 \%$ and the farming area used in the second paddy growth season should be decreased by $10 \%$.
\end{abstract}

\section{INTRODUCTION}

The Intergovernmental Panel on Climate Change (IPCC) has stated that the observed increase in global average temperature since the mid-20th century is very likely due to the observed increases in anthropogenic greenhouse gas concentrations (IPCC 2007). Climate change has led to increased temperature, rising sea levels, and increased rainfall intensity. Thus, we will face more extreme weather events in the future.

Taiwan, located in the West Pacific, is a climate change impact hot spot. Some studies indicated that Taiwan's surface temperature will rise in the future (Lin et al. 2009; Hsu et al. 2011). The temporal precipitation distribution may become more uneven, and rainless days might occur more frequently (Huang et al. 2012, 2014a). The changes in hydrologic projections indicate that water resources management in Taiwan could become a challenging task. The climate change impact on the Shihmen Reservoir water supply in Northern Taiwan has been assessed by numerous authors (Lee and Huang 2014; Huang et al. 2014b). The results show that reduced inflow and increased demand will result in drought for the Shihmen Reservoir supply zone.

\footnotetext{
* Corresponding author

E-mail:b0137@mail.ntou.edu.tw
}

The purpose of this study is to assess climate change effects on water resources in the Zhoshui River basin in the Changhua and Yunlin areas of Central Taiwan (Fig. 1). This area is crucial for rice production in Taiwan. However, the area has suffered from severe land subsidence (Tung and $\mathrm{Hu}$ 2012; Hung et al. 2012), limiting the potential for groundwater pumping. Therefore, understanding the impact of climate change on this area's water resources system is essential.

The Zhoshui River originates in the Central Mountain Range. Figure 1 shows the Zhoshui River basin water resources infrastructure. Figure 2 depicts the basin water resources system. The Wushe Reservoir has a catchment area of $219 \mathrm{~km}^{2}$ and is used for hydropower. Its operating rule curve (Fig. 3a) indicates that the reservoir will generate as much electricity as possible if the water surface level is above the rule curve. Otherwise, it will generate electricity according to the inflow. The Wujie Dam raises the water level and conveys water to the Sun-Moon-Lake Reservoir. Sun-Moon-Lake is the largest off-site reservoir in this basin. Although pumped-storage hydroelectricity is its main objective, it supports the water supply when the water from the main stream cannot satisfy the demand. Figure $3 \mathrm{~b}$ indicates that if the Sun-Moon-Lake Reservoir water surface 


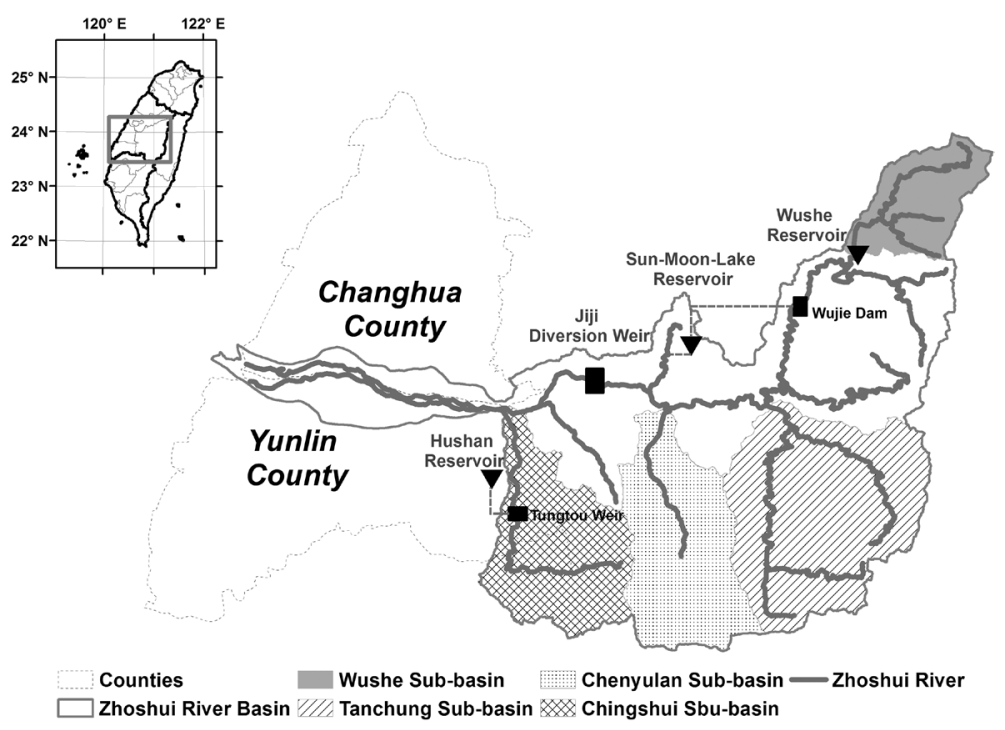

Fig. 1. Location and related water resource infrastructures of the study area.

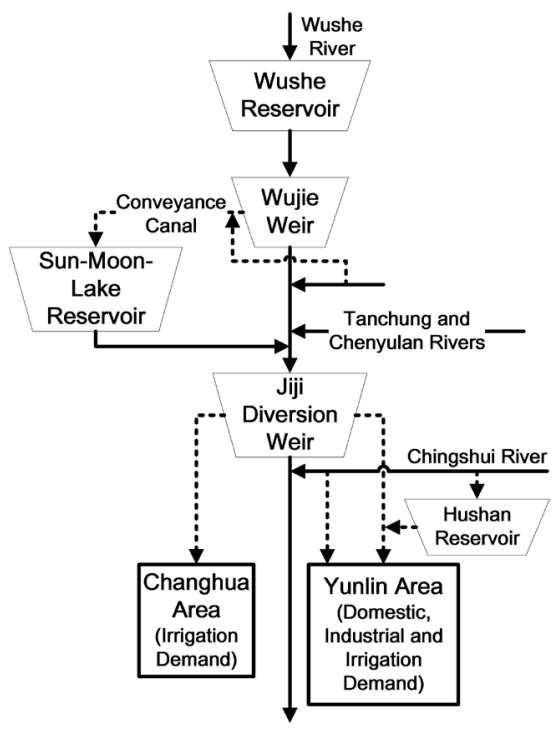

Fig. 2. Conceptual water resources system of the Zhoshui River Basin.

(a)

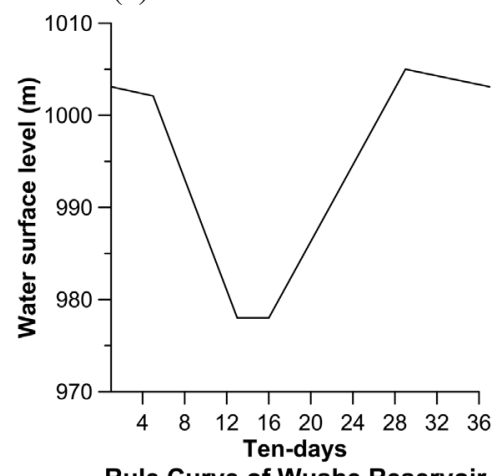

(b)

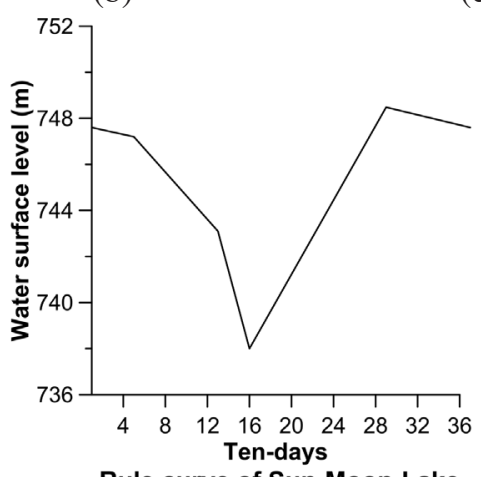

Rule curve of Sun-Moon-Lake (c) $\square$ Irrigation $\square$ Industrial $\square$ Domestic

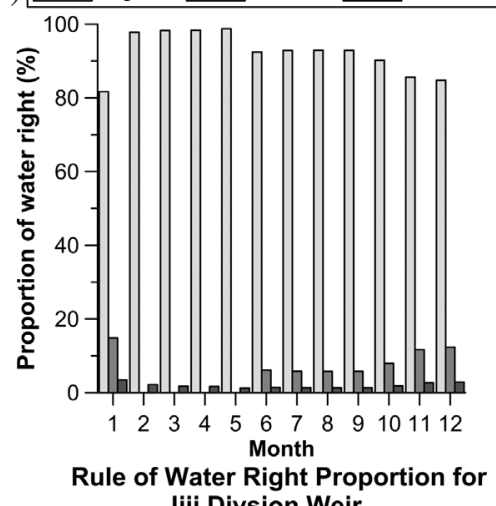

Jiji Divsion Weir

Fig. 3. The operation rules for (a) Wushe reservoir, (b) Sun-moon-lake reservoir, and (c) Jiji division weir. 
level is over the rule curve, the reservoir release meets the maximum hydropower and downstream use requirements. Otherwise, it is at the minimum level for hydropower and downstream requirements. There are two tributaries in the midstream section, the Tanchung and Chenyulan Rivers, which encompass 700 and $450 \mathrm{~km}^{2}$, respectively. The water resources in the upstream and midstream section eventually converge into the Jiji Division weir (with a catchment area of $2304 \mathrm{~km}^{2}$ ). This weir is the Zhoshui River basin management center and is responsible for the Changhua and Yunlin area demand. If the Jiji Division weir storage is lower than the total demand, the release for different water users (irrigation, domestic, and industrial) should be in accordance with their water rights (Fig. 3c). Industrial users have no water rights from February through May.

Hushan is a newly built reservoir with a catchment area of $259 \mathrm{~km}^{2}$. It is an off-site reservoir and receives Chingshui River flow from the intake at the Tungtou weir. The main task of this reservoir is to satisfy domestic demand and reduce groundwater pumping in Yunlin.

In the impact assessment performed in this study, we (1) calculated the Changhua and Yulin irrigation water requirements (in which agriculture is the main sector), (2) estimated the Zhoshui River basin streamflow, and (3) simulated the water resources system according to hydrological data. We then assessed the impact of climate change through a comparison between the present $(2001-2010)$ and the future (2046 - 2065).

\section{DATA AND METHODS}

\subsection{Meteorological Projections}

General circulation models (GCMs) are the most advanced tools available for simulating the global climate system response to increasing greenhouse gas concentrations. This study focuses on the projected conditions for the years 2046 - 2065. Meteorological data projections (precipitation and temperature) based on the A1B scenario (Nakicenovic and Swart 2000) were adopted from the following five GCMs: (1) CGCm3 from the Canadian Center for Climate Modeling and Analysis (CCCma), (2) $\mathrm{Cm} 3$ from the Centre National de Recherches Meteorologiques (CNRM), (3) Mk3.0 from Australia's Commonwealth Scientific and Industrial Research Organization (CSIRO), (4) Cm2.0 from the Geophysical Fluid Dynamics Laboratory (GFDL), and (5) FGOALS-g1.0 from the State Key Laboratory of Numerical Modeling for Atmospheric Sciences and Geophysical Fluid Dynamics (LASG). The original GCM outputs have coarse resolutions that cannot be directly applied to watershed scale calculations. Statistical downscaling from GCM scenario-run grids to local meteorological stations is therefore necessary. We obtained the aforementioned GCM downscaled projections from the Global Change Research Center of National Taiwan University. The downscaling process can be briefly explained as follows: (1) the GCM output near Taiwan was adjusted with respect to the National Centers for Environmental Prediction (NCEP) reanalysis data through the training period by linking the normalized probability distribution function of the mean climate parameters; (2) transfer functions such as multiple-variant linear regression were established to link the NCEP reanalysis variants with local records through the training period; (3) meteorological projections at each station through the verification period were adjusted with respect to local records using the first stage procedure, and the established linkage was then extended to adjust the forward projection. For more downscaling process details, please refer to Kalnay et al. (1996) and Lin et al. (2009, 2010).

\subsection{Paddy Water Requirement}

The crop water requirement relates directly to the crop variety and the field evapotranspiration. The Food and Agriculture Organization (FAO) of the United Nations uses the following equation to estimate the crop water requirement grown in large fields under disease-free and well-fertilized conditions (Allen et al. 2006):

$E T_{c}=K_{c} \times E T_{o}$

where $E T_{c}$ and $E T_{o}$ are the crop and reference evapotranspiration (mm day ${ }^{-1}$ ), respectively, and $K_{c}$ is a crop coefficient (dimensionless).

$K_{c}$ is based on a distribution instead of a constant throughout the growth duration and differs depending on the crop variety. Shih et al. (1996) proposed a $K_{c}$ for paddy rice in Taiwan; the $K_{c}$ values for the first and second cropping seasons are shown in Table 1.

To estimate reference evapotranspiration, $E T_{o}$, the FAO Penman-Monteith (PM) equation is recommended (Allen et al. 2006):

$E T_{o}=\frac{0.408 \Delta\left(R_{n}-G\right)+\gamma \frac{900}{T+273} u_{2}\left(e_{s}-e_{a}\right)}{\Delta+\gamma\left(1+0.34 u_{2}\right)}$

where $\Delta$ and $\gamma$ are the saturation vapor pressure curve slope and the psychrometric constant $\left(\mathrm{kPa}^{\circ} \mathrm{C}^{-1}\right)$, respectively. $R_{n}$ and $G$ are the net radiation at the crop surface and the soil heat flux density $\left(\mathrm{MJ} \mathrm{m}^{2} \mathrm{day}^{-1}\right)$, respectively. $T$ is the mean daily air temperature at a height of $2 \mathrm{~m}\left({ }^{\circ} \mathrm{C}\right) \cdot e_{s}$ and $e_{a}$ are the saturation and actual vapor pressure $(\mathrm{kPa})$, respectively. $u_{2}$ is the wind speed at a height of $2 \mathrm{~m}_{\left(\mathrm{m} \mathrm{s}^{-1}\right)}$.

Because only daily temperature and precipitation are available from the GCM projections, information for the PM equation is insufficient for evapotranspiration estimation for future scenarios. Instead, the Hamon method, a 
temperature-based equation for estimating evapotranspiration, was used (Shaw and Riha 2011):

$$
P E=29.8 N_{h} \frac{e_{s}}{T+273.2}
$$

where $P E$ is the potential evapotranspiration according to the Hamon method (mm day ${ }^{-1}$ ) and $N_{h}$ is the sunshine duration (hours). The theoretical future $N_{h}$ was defined as in Allen et al. (2006).

\subsection{Bias Correction}

$E T_{o}$ is regarded as a standard to be followed; therefore, the estimated $P E$ value must be corrected. The quadrant transformation method (Huang et al. 2012) was applied in this study for bias correction. Figure 4 shows the quadrant transformation method concept, in which the curve indicates the percentage of time that evapotranspiration is equaled or exceeded during the period of study. The difference between the first and fourth quadrants was estimated from observations or projections, whereas the difference between the third and fourth quadrants was due to climate change. The curve in the second quadrant yields the corrected $P E$ and was produced by conversions in the other three quadrants.

The bias correction process can be described by the following steps: (1) constructing the curves that indicate the percentage of time equaled or exceeded (Searcy 1959) in the first (observations in the present), third (projections in the future), and fourth (projections in the present) quadrants; (2) determining the corresponding percentile in the fourth quadrant using the given projection in the third quadrant; (3) finding a new value in the first quadrant and point in the second quadrant based on the percentile; and (4) repeating steps (2) and (3) to obtain the curve for the correction in the second quadrant.

Monthly bias correction was adopted in this study

Table 1. $K_{c}$ distribution, accumulation of growing degree days and limit of ponding storage for growth stages of paddy rice.

\begin{tabular}{cccccc}
\hline Growth stages & $\begin{array}{c}\boldsymbol{K}_{\boldsymbol{c}} \text { in the first } \\
\text { cropping season } \\
\text { (February - June) }\end{array}$ & $\begin{array}{c}\boldsymbol{K}_{\boldsymbol{c}} \text { in the second } \\
\text { cropping season } \\
(\text { July - November) }\end{array}$ & $\begin{array}{c}\text { Accumulation of } \\
\text { growing degree days } \\
\left({ }^{\circ} \mathbf{C} \text {-days }\right)\end{array}$ & $\begin{array}{c}\text { Lower limit of } \\
\text { tolerable ponding } \\
\text { depth (mm) }\end{array}$ & $\begin{array}{c}\text { Upper limit of } \\
\text { tolerable ponding } \\
\text { depth }(\mathbf{m m})\end{array}$ \\
\hline Vegetative stage I & 0.5 & 0.9 & 269 & 30 & 50 \\
Vegetative stage II & 0.8 & 1.2 & 538 & 20 & 30 \\
Vegetative stage III & 1.2 & 1.5 & 807 & 0 & 20 \\
Reproductive stage I & 1.3 & 1.6 & 980 & 50 & 100 \\
Reproductive stage II & 1.3 & 1.5 & 1153 & 50 & 100 \\
Ripening stage I & 1.2 & 1.3 & 1343 & 50 & 100 \\
Ripening stage II & 1.1 & 1.1 & 1534 & 20 & 30 \\
Ripening stage III & 0.7 & 0.6 & 1725 & 0 & 20 \\
\hline
\end{tabular}

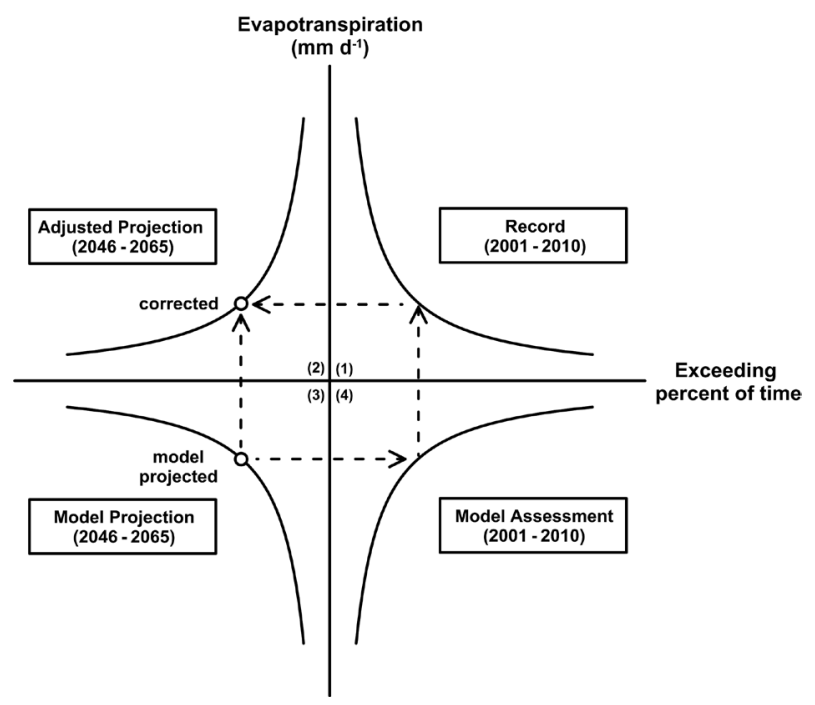

Fig. 4. Quadrant transformation method concept. 
based on seasonal variations. The above statement could be expressed as the equation:

$x_{c r t .}^{F}=f_{o b s .}^{P-1}\left[f_{\text {proj. }}^{P}\left(x_{\text {proj. }}^{F}\right)\right]$

where $x$ is the daily potential evapotranspiration $(\mathrm{mm}) ; f$ and $f^{-1}$ are the function and inverse function of the monthly curves that indicate the percentage of time equaled or exceeded. The superscripts $P$ and $F$ represent the present and future time, respectively; and the subscripts $o b s .$, proj., and crt. symbolize the observation data, GCMs projections, and corrected data, respectively.

\subsection{Paddy Development Mechanism}

Calendars are often used to predict crop development for management. However, calendar days can be misleading, particularly during early crop growth stages (Miller et al. 2001). In addition, climate change complicates using constant days to represent each growth stage.

Numerous studies have found that crop growth is directly related to temperature (Russelle et al. 1984; Eskridge and Stevens 1987). Therefore, the phenology crop model can be constructed according to the growing degree days (GDD) equation:

$\mathrm{GDD}=\sum\left(T-T_{b}\right)_{i}=\sum(\Delta T)_{i}$

$\Delta T=0$ if $T-T_{b} \leq 0$

where $T_{b}$ is the base temperature for a crop variety. $\Delta T$ is set to 0 if the daily temperature is less than $T_{b}$; thus, the crop stops developing at that time (Gilmore and Rogers 1958).

The GDD equation is a simple thermal time equation. It accumulates thermal time linearly with increasing temperature above a constant crop-specific base temperature.
Theoretically, if thermal time is accumulated correctly for a given crop variety, crop development should then be directly related to thermal time accumulation (i.e., GDD). The GDD equation indicates that each crop growth stage is related to the accumulation of thermal time, regardless of the planting time or location (Hodges 1991).

For paddy rice, $T_{b}$ is generally set to $10^{\circ} \mathrm{C}$ (Hardke et al. 2013). Moreover, the GDD accumulation value is set to $1725{ }^{\circ} \mathrm{C}$-days according to recommendations for the common paddy variety in Taiwan (Hualien District Agricultural Research and Extension Station 2006, 2007). The GDD accumulation details for each paddy growth stage are shown in Table 1.

\subsection{Irrigation Water Requirement}

A paddy field water balance model is presented in Fig. 5. We applied it to calculate the irrigation water requirement. Considering different soil types in paddy fields and the irrigation canal water conveyance loss, the continuity equation for a paddy field is expressed as follows:

$S_{t+1}=S_{t}+P_{t}-E T_{c t}-\sum_{j} f_{j} A_{j}{ }^{\circ}+\frac{I R_{t}}{\sum_{i} A_{i}^{*}\left(1+C L_{i}\right)}$

where $S_{t}, P_{t}, E T_{c t}$, and $I R_{t}$ indicate the daily water storage, rainfall, crop evapotranspiration, and irrigation water requirement in the paddy fields at time $t\left(\mathrm{~mm} \mathrm{day}^{-1}\right)$, respectively. $f_{j}$ is the percolation rate of the $j$ th soil type $\left(\mathrm{mm} \mathrm{day}^{-1}\right), A_{j}{ }^{\circ}$ is the percentage of the $j$ th soil type area $(\%), A_{i}^{*}$ denotes the percentage of total farming area controlled by the $i$ th canal (\%), and $C L_{i}$ is the average water conveyance loss in the area controlled by the $i$ th canal (\%).

The irrigation water requirement must be externally supplied to offset the deficit for paddy growth when precipitation and storage do not satisfy water demand. By

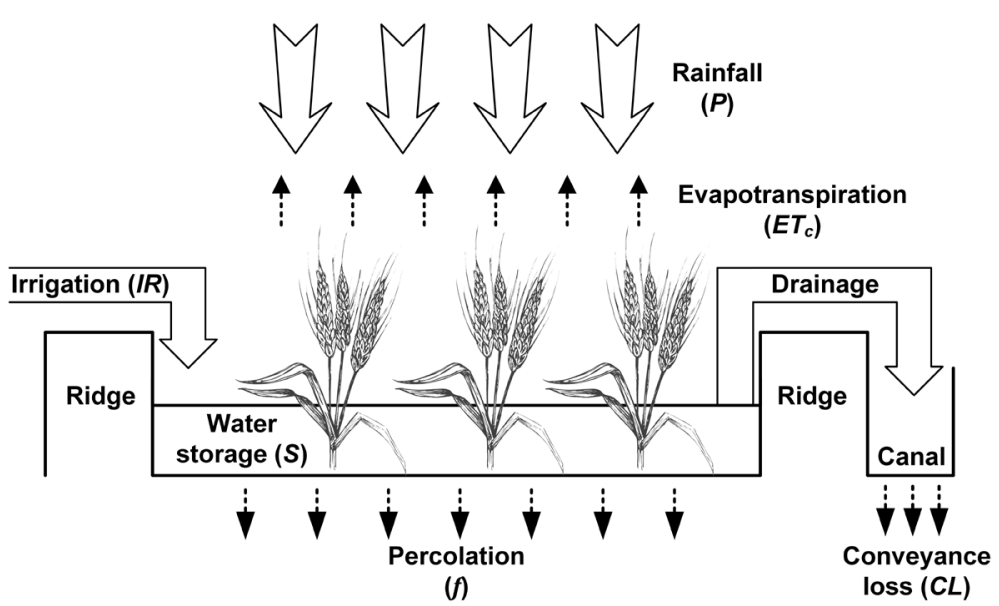

Fig. 5. Conceptual model for water balance in paddy fields. 
contrast, the irrigation water requirement is 0 when demand is satisfied. Therefore, Eq. (6) can be rewritten as follows:

$$
\begin{aligned}
& I R_{t}=\sum_{i} A_{i}^{*}\left(1+C L^{i}\right) \cdot\left(E T_{c t}+\sum_{j} f^{j} A_{j}{ }^{\circ}+S_{t}^{\min }-S_{t}-P_{t}\right) \\
& \text { if } S_{t}+P_{t}-E T_{c t}-\sum_{j} f^{j} A_{j}{ }^{\circ}<S_{t}^{\min }
\end{aligned}
$$

The rainfall stored in the paddy field for growth is termed the effective rainfall $\left(P_{t}^{*}\right)$ at time $t$; hence,

$$
P_{t}^{*}=\min \left\{S_{t}^{\max }-S_{t}+E T_{c t}+\sum_{j} f_{j} A_{j}^{\circ}, P_{t}\right\}
$$

where $S_{t}^{\max }$ and $S_{t}^{\text {min }}$ are the upper and lower limits of tolerable ponding depth for paddy during different growth stages (mm), respectively (Table 1).

\subsection{Rainfall-Runoff Model}

The tank model (Sugawara 1961) was adopted to assess stream flow in the climate change context in this study. As the tank model is a conceptual and deterministic rainfallrunoff model composed of several tanks that accounts for a watershed storage effect. In other words, the tank model effective simulation performance is due to continuous damping and lagging effects (Lee 1993). The tank model advantages include a simple structure, easy calculations and reasonable functions (Yokoo and Kazama 2012).

Figure 6 shows the runoff mechanism for a 2-layer tank model. When precipitation reaches the height of ha ${ }_{1}$ in the top tank, the watershed is saturated. If the water surface depth in the top tank is over $\mathrm{ha}_{1}$, additional precipitation discharges from the tank through orifice $\mathrm{a}_{1}$. This process is the major component of surface runoff. In a high-intensity storm, the top tank water surface depth is higher than $\mathrm{ha}_{2}$. The outflow through orifice $\mathrm{a}_{2}$ represents the runoff in this scenario. Orifice $a_{0}$ simulates the percolation process in a watershed, in which the water is transported into the ground. The bottom of the 2-layer tank model represents the interflow and groundwater and is opposite the top tank. Parameter $h b_{1}$ is a threshold that is similar to ha $a_{1}$. The discharge through orifice $b_{1}$ represents the outflow of interflow and groundwater.

Six parameters in the 2-layer tank model require calibration. We used the multi-start Powell method to calibrate the tank model parameters. The Powell method is an efficient and robust conjugate direction method used to find the minimum of a function (Powell 1964). An inappropriate initial point converges toward a local minimum instead of a global minimum when the problem structure is more complex. As an improvement, the multi-start Powell method can overcome the Powell method disadvantages through providing several initial points. Tanakamaru (1995) suggested that the multi-start Powell method is an effective and powerful tool for tank model parameter calibration. Chen et al. (2005) recommended that the number of initial points should be equal to or more than 50 to avoid searching failure.

The parameter search boundaries for tank model calibration are shown in Table 2. If the orifice coefficient summation of each tank is more than 1 , the tank outflow might be greater than the inflow and storage summation. To avoid this illogical relationship, the orifice coefficient of the top tank must be subject to the following equation during calibration:

$\mathrm{a}_{0}+\mathrm{a}_{1}+\mathrm{a}_{2} \leq 1$

Additionally, we selected the average percentage error as the objective function during tank model parameter calibration:

$$
o b j=\sum \frac{\left|Q_{t}^{o b s}-Q_{t}^{s i m}\right|}{Q_{t}^{o b s}} \div N_{d}
$$

where $Q_{t}^{\text {obs }}$ and $Q_{t}^{\text {sim }}$ are the observed and tank model-simulated discharges, respectively. $N_{d}$ denotes the number of simulation days.

\subsection{Simulation Assessment Indices}

We used the degree of satisfaction, reliability and shortage index $(S I)$ to represent the water resources simulation performance. The definition of these indices is provided in the following equations:

degree of satisfaction $=\frac{S P L}{D M}$

degree of reliability $=\frac{N_{s}}{N_{d}}$

$S I=\frac{100}{N_{y}} \sum\left(1-\frac{S P L}{D M}\right)^{2}$

where $S P L$ and $D M$ are the supplied water and water demand, respectively $\left(\mathrm{m}^{3}\right) . N_{s}$ is the total satisfied days, and $N_{y}$ indicates the simulation time in years.

\section{MODEL VALIDATION}

\subsection{Validation of Bias Correction}

Figure 7 shows the difference before and after bias correction for evapotranspiration. The curve distributions indicating the percentage of time equaled or exceeded between observations and projections in the present (first and fourth 

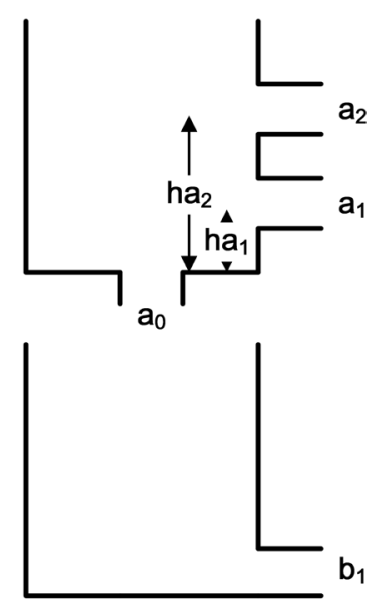

Fig. 6. A two-layer tank model.

Table 2. Searching boundaries of the two-layer tank model parameters.

\begin{tabular}{c|cccc|cc}
\hline \multirow{2}{*}{ Parameters } & \multicolumn{4}{|c|}{ Orifice coefficient $\left(\right.$ day $\left.^{-1}\right)$} & \multicolumn{2}{c}{ Orifice height (mm) } \\
\cline { 2 - 7 } & $\mathbf{a}_{\mathbf{0}}$ & $\mathbf{a}_{\mathbf{1}}$ & $\mathbf{a}_{\mathbf{2}}$ & $\mathbf{b}_{\mathbf{1}}$ & $\mathbf{h} \mathbf{a}_{\mathbf{1}}$ & $\mathbf{h a}_{\mathbf{2}}$ \\
\hline $\begin{array}{c}\text { lower-upper } \\
\text { boundary }\end{array}$ & $0-1$ & $0-1$ & $0-1$ & $0-1$ & $0-500$ & $0-500$ \\
\hline
\end{tabular}

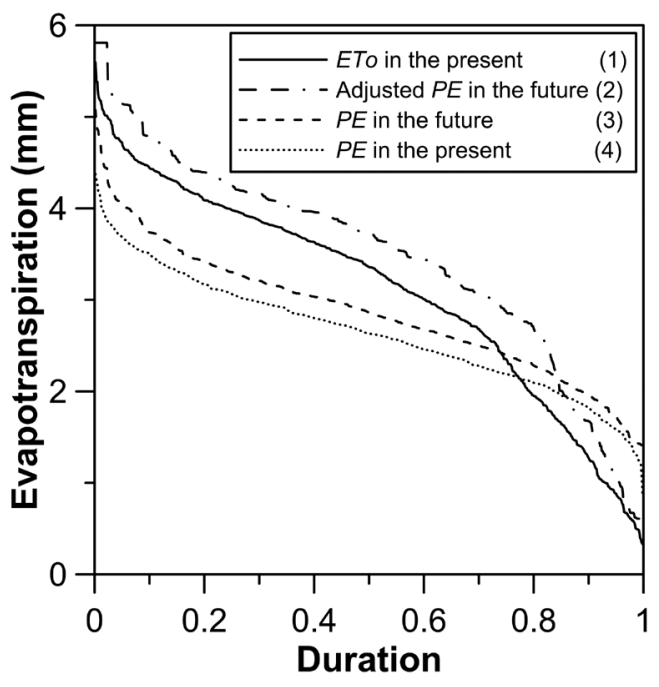

Fig. 7. Comparison of the exceeding percent time curves for evapotraspiration at each quadrant in March (LASG GCM).

quadrant) are quite different. However, after the quadrant transformation, the distribution of adjusted data (second quadrant) is more similar to the observations (first quadrant).

\subsection{Water Balance Model Validation for Irrigation}

Figure 8 shows the observed water consumption and estimated water requirements for paddy rice in the Chan- ghua and Yunlin areas. The bias range is approximately 2.3 - 34.6\% in Changhua and $0.2-87.8 \%$ in Yunlin. On average, the biases through the first and second paddy growth seasons (approximately February - June and July - November) are 10.8 and $16.1 \%$ in Changhua and 17.0 and $30.0 \%$ in Yunlin, respectively.

This difference might arise owing to variations in hydrological conditions. The irrigation consumption records are based on actual water received from canals, whereas the model estimations assume that irrigation requirements can be fulfilled with abundant water. For example, (1) there is considerable underestimation in 2002 in Yunlin in the second paddy growth season (Fig. 8d). Because 2002 was a dry year, managers decided to transfer most of the water to Changhua rather than Yunlin (Fig. 8b); (2) there is overestimation in Yunlin throughout 2005 and 2006 because these two years were wet, and more water could be supplied to Yunlin (Figs. 8c and d).

The report of Water Resources Angecy proposed that crop water requirement minus effective rainfall throughout the whole paddy growth season should range between 1136 - $1317 \mathrm{~mm}$ in Changhua and Yunlin area (Kan 2002). If considering conveyance loss, the proposed irrigation consumption will be approximately $1550-1800 \mathrm{~mm}$. Following the standard, the irrigation water requirement estimation (Fig. 8) is reasonable when using the water balance model. Excluding 2002, 2005, and 2006, the differences in Changhua between the observations and estimations in the first and second paddy growth seasons are 11.4 and $14.8 \%$, respectively. The differences in Yunlin are 13.9 and $17.0 \%$, respectively.

Currently, the planned farming areas in Changhua in the first and second paddy growth seasons are 370.3 and $390.8 \mathrm{~km}^{2}$, respectively. The areas in Yunlin are 106.7 and $369.9 \mathrm{~km}^{2}$, respectively. By multiplying the estimated values from 2001 - 2010, the annual irrigation volume requirement is nearly 1.9 billion $\mathrm{m}^{3}$, which is close to the annual irrigation supply from the Jiji division weir at 1.8 billion $\mathrm{m}^{3}$.

\subsection{Tank Model Validation}

Wushe, Tanchung, Chenyulan, and Chingshui are the four sub-basins selected for constructing the tank model for the Zhoshui River basin (Fig. 1). The river flow gauges at these four sub-basins are unaffected by water-related infrastructures such as reservoirs. These sub-basins cover about $60 \%$ of the basin area. In the rest of the area, the area ratio is applied to estimate river flow. For example, the Chingshui River flow below the Tungtou weir $\left(154 \mathrm{~km}^{2}\right)$ is equal to 0.59 times the Tungtou weir flow $\left(259 \mathrm{~km}^{2}\right)$.

We used 8-yr data for parameter calibration and the remaining 2 years (2009 - 2010) for verification. Table 3 shows the tank model calibrated parameters. The annual differences in volume in the four main sub-basins are verified 
between $3.7-13.1 \%$. In addition, the bias throughout the wet season (May - October) is higher than in the dry season (November - April), except in the Tanchung sub-basin (Table 4). Figure 9 shows the daily discharge validation in the sub-basins and demonstrates that the tank model is able to simulate the river flow characteristics in these sub-basins. In addition, when applying the tank model we assumed that the watershed characteristics will remain unchanged in the future - in other words, that the parameters identified for the current climate will remain valid.

\section{RESULTS AND DISSCUION}

\subsection{Projection of Meteorological Data}

Figure 10 illustrates the temporal precipitation and temperature distributions. Note that the meteorological data in the Zhoshui River basin are a weighted average of the sub-basins.

According to precipitation projections, the annual precipitation in the Zhoshui basin in the future (2046 - 2065) will range from 2104.0 - $2489.9 \mathrm{~mm}$, with an average of $2287.5 \mathrm{~mm}$. Based on the current annual precipitation
(2469.7 mm for 2001 - 2010), most GCMs project a decrease in the future $(-14.8-0.8 \%)$. On average, the precipitation projections are $7.4 \%$ lower than at present. However, the temporal precipitation distribution in the Zhoshui basin indicates that more fluctuations would occur in each month, especially in July and August (see top left graph of Fig. 10).

The precipitation projections for the upstream and downstream areas are similar. However, the monthly precipitation distribution in the future has obvious fluctuations. As the top center and top right graphs of Fig. 10 indicate, the temporal precipitation distribution will be more uneven in both areas in the future. The difference between the average annual precipitation in the present and future is insignificant. The present annual precipitation levels in Changhua and Yunlin are 1435.9 and $1878.7 \mathrm{~mm}$, respectively. For Changhua, the variations in projections of annual precipitation are between -241.9 and $260.1 \mathrm{~mm}(-16.8-18.1 \%)$, with an average of $33.4 \mathrm{~mm}(2.3 \%)$. For Yunlin, the variations in projections of annual precipitation are between -270.1 and $578.8 \mathrm{~mm}(-14.4-30.8 \%)$, with an average of $49.6 \mathrm{~mm}$ (2.6\%).

Temperature projections for the Zhoshui basin show
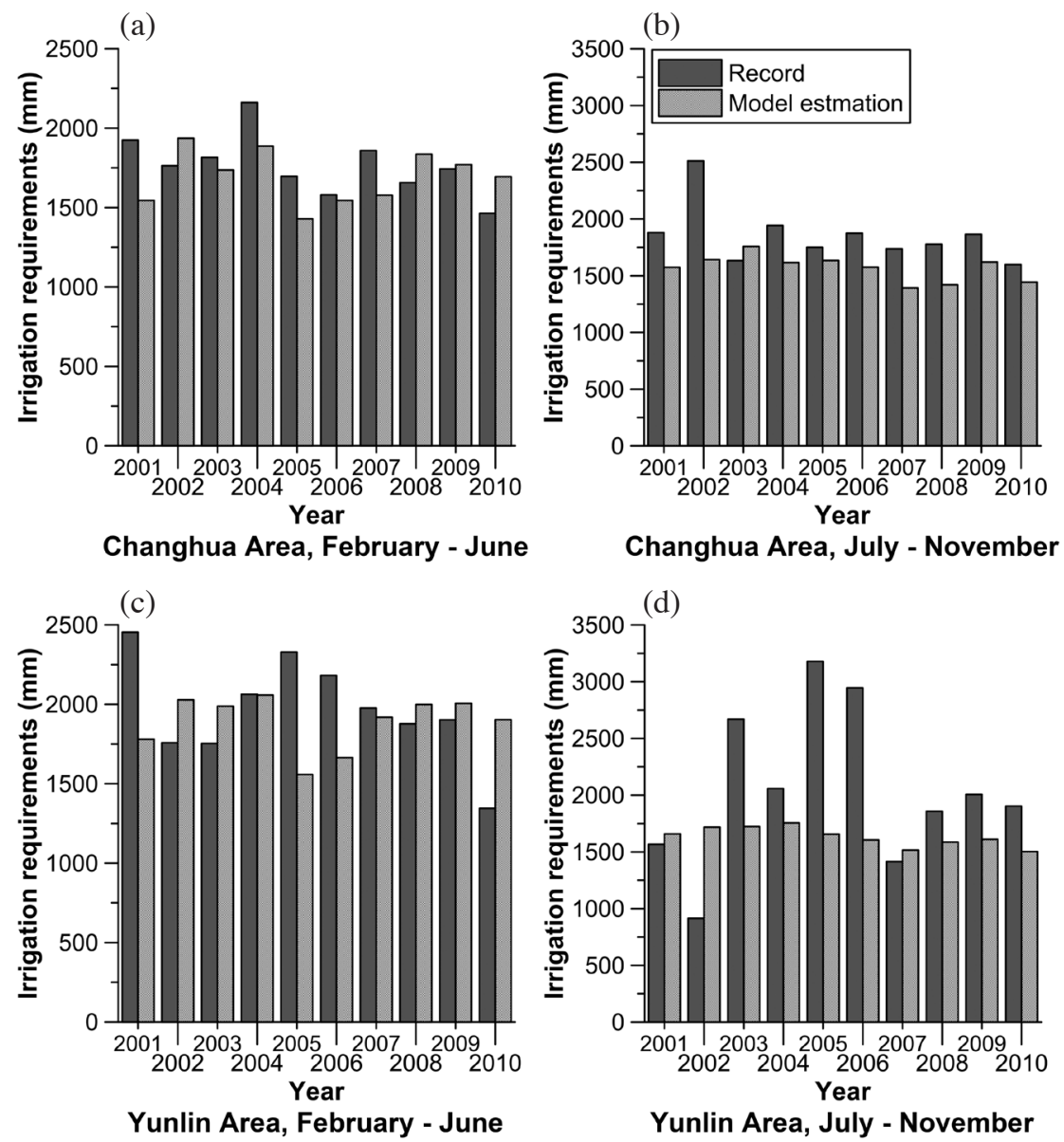

Fig. 8. Comparison of paddy water requirements between recorded consumption and model estimation in 2001 - 2010: (a) Changhua area in February - June; (b) Changhua area in July - November; (c) Yunlin area in February - June; (d) Yunlin area in July - November. 
Table 3. Result of calibration for four main sub-basins of the Zhoshui River.

\begin{tabular}{c|rrrr|rc}
\hline \multirow{2}{*}{ Sub-Basins } & \multicolumn{3}{|c|}{ Orifice coefficient $\left(\mathbf{1 0}^{-\mathbf{3}} \mathbf{d a y}^{-\mathbf{1}}\right)$} & \multicolumn{2}{c}{ Orifice height $(\mathbf{m m})$} \\
\cline { 2 - 7 } & \multicolumn{1}{|c}{$\mathbf{a}_{\mathbf{0}}$} & \multicolumn{1}{c}{$\mathbf{a}_{\mathbf{1}}$} & \multicolumn{1}{c}{$\mathbf{a}_{\mathbf{2}}$} & $\mathbf{b}_{\mathbf{1}}$ & $\mathbf{h}_{\mathbf{1}}$ & $\mathbf{h}_{\mathbf{2}}$ \\
\hline Wushe & 9.8 & 17.7 & 121.5 & 18.0 & 13.9 & 151.1 \\
Tanchung & 38.1 & 13.3 & 63.9 & 15.3 & 0.0 & 112.7 \\
Chenyulan & 40.3 & 57.4 & 156.0 & 12.4 & 18.9 & 118.6 \\
Chingshui & 10.4 & 177.7 & 394.3 & 28.0 & 61.5 & 149.5 \\
\hline
\end{tabular}

Table 4. Tank model validation in volume error for four main sub-basins of the Zhoshui River in 2009 - 2010 (unit in \%).

\begin{tabular}{l|rccc}
\hline & Wushe & Tanchung & Chenyulan & Chingshui \\
\hline Whole year & +13.1 & +3.7 & +10.8 & +11.9 \\
Wet season & +14.5 & +2.1 & +11.4 & +13.1 \\
Dry season & +8.8 & +9.5 & +8.5 & -7.9 \\
\hline
\end{tabular}

Note: “+” means overestimation; “-” means underestimation.


Fig. 9. Comparison of daily discharge between observation and tank model projection for four main sub-basins of the Zhoshui River in 2009 2010 . 

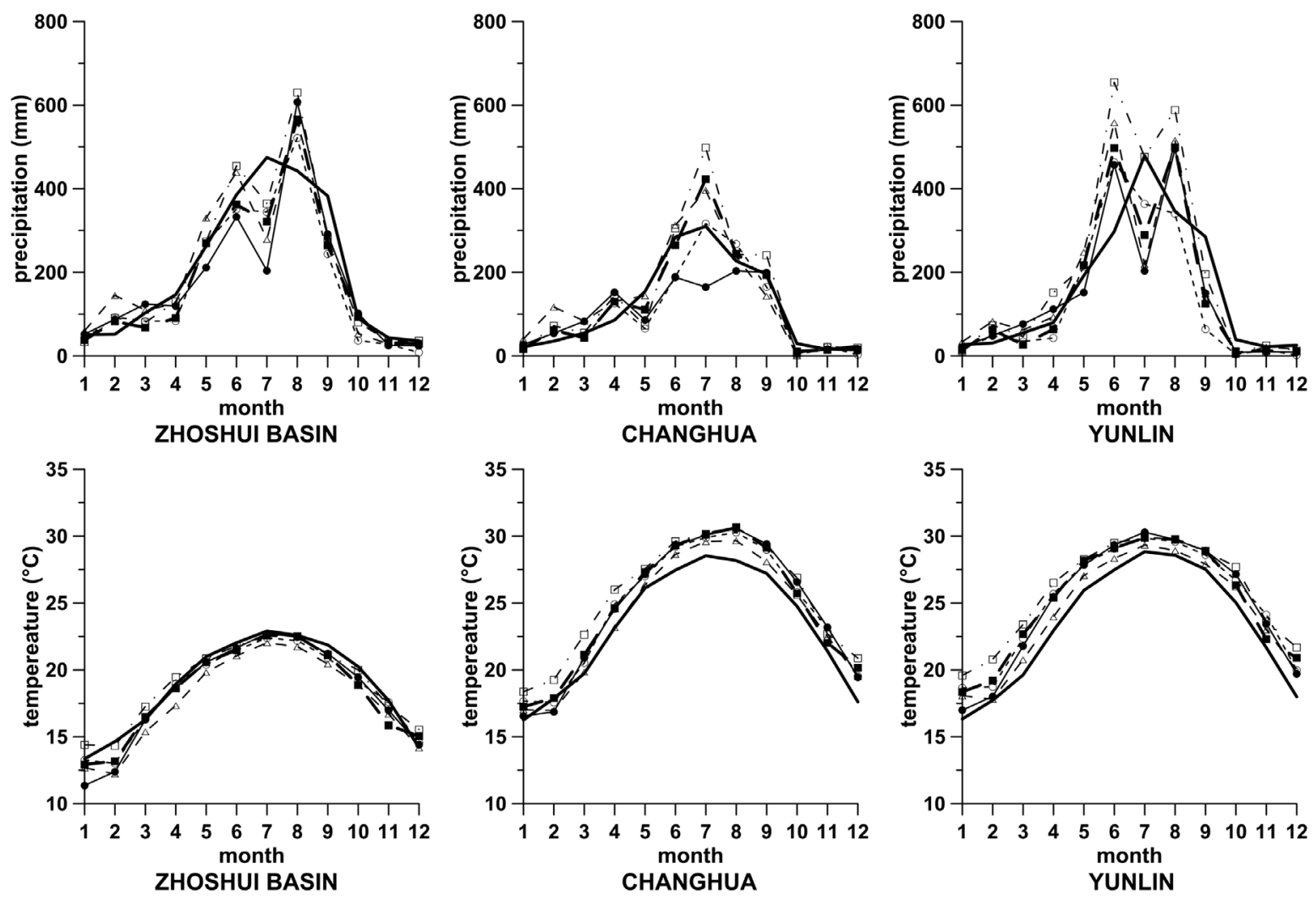

Fig. 10. Comparison of precipitation and temperature between the present (2001 - 2010) and future (2046 - 2065).

that the difference in the annual mean between the present and future is insignificant. The weighted annual temperature average in the Zhoshui basin is currently $18.8^{\circ} \mathrm{C}$. The variations in projections are between -1.1 and $0.1^{\circ} \mathrm{C}(-5.9-0.6 \%)$, and the average decrease in the future is $0.5^{\circ} \mathrm{C}(2.8 \%)$. By contrast, the variations in temperature projections for Changhua and Yunlin are significant. For Changhua, the increment in annual mean temperature projections range from $0.7-2.1^{\circ} \mathrm{C}(3.1-9.2 \%)$, with an average of $1.4^{\circ} \mathrm{C}(6.0 \%)$. For Yunlin, the increment in annual temperature projections range from $1.0-2.5^{\circ} \mathrm{C}(4.2-10.7 \%)$, with an average of $1.7^{\circ} \mathrm{C}(7.4 \%)$. Both areas exhibit increasing tendencies.

\subsection{Impact of Climate Change on Irrigation Water Requirements}

Table 5 shows that, compared with the present irrigation requirement (2001 - 2010), the projected irrigation water requirement for 2046 - 2065 increases slightly, within the range of $19.4-155.6 \mathrm{~mm}(1.2-9.5 \%)$. GCMs projections indicate that the monthly mean temperature in the future will increase $0.5-3.0^{\circ} \mathrm{C}$ on average, as shown in Fig. 10. Rising temperature will certainly cause crop water requirements $\left(E T_{c}\right)$ to increase during $2046-2065$. The in- crements of $E T_{c}$ are within 85.0 - $132.4 \mathrm{~mm}(16.1-22.0 \%)$ throughout each paddy growth season in the Changhua and Yunlin areas.

However, rising temperatures associated with GDDs will reduce the growth duration. Compared to the present growth duration, the future growth duration of paddy crops will decrease by $5.2-10.7$ days in both areas. Hence, there is a marked increment in $E T_{c}$, but the irrigation requirement increment will be smaller than $10 \%$ in the future.

\subsection{Impact of Climate Change on River Flow}

In 2046 - 2065, the annual precipitation in these subbasins will decrease, except in Wushe. On average, the projected annual precipitations in the Tanchung, Chenyulan, and Chingshui sub-basins decrease by 404.4, 439.1, and $22.4 \mathrm{~mm}(20.9,17.9$, and $0.7 \%)$, respectively. Wushe is projected to increase by $754.2 \mathrm{~mm}(24.9 \%)$ in the future. Consequently, the variations in projected annual discharge in the sub-basins are approximately $-272-3$ million $\mathrm{m}^{3}$ (-33.3 - 0.5\%). Figure 11 shows a comparison of temporal distributions of river flow between the present and future. Overall, an obvious decrease will occur in the discharge of the Zhoshui River from July to December. 
Table 5. Annual irrigation water requirement during the present (2001 - 2010) and the future (2046 - 2065).

\begin{tabular}{|c|c|c|c|c|c|c|c|c|}
\hline \multirow{2}{*}{ Irrigation water requirement $(\mathrm{mm})$} & \multirow{2}{*}{ Cropping seasons } & \multirow{2}{*}{ Present } & \multicolumn{6}{|c|}{ Future } \\
\hline & & & CCCma & CNRM & CSIRO & GFDL & LASG & Average \\
\hline \multirow{2}{*}{ Changhua Area } & February - June & 1696 & 1749 & 1832 & 1744 & 1663 & 1660 & 1730 \\
\hline & July - November & 1568 & 1595 & 1598 & 1583 & 1454 & 1707 & 1587 \\
\hline \multirow{2}{*}{ Yunlin Area } & February - June & 1890 & 1994 & 2064 & 2017 & 1857 & 1863 & 1959 \\
\hline & July - November & 1633 & 1750 & 1887 & 1781 & 1656 & 1869 & 1789 \\
\hline
\end{tabular}
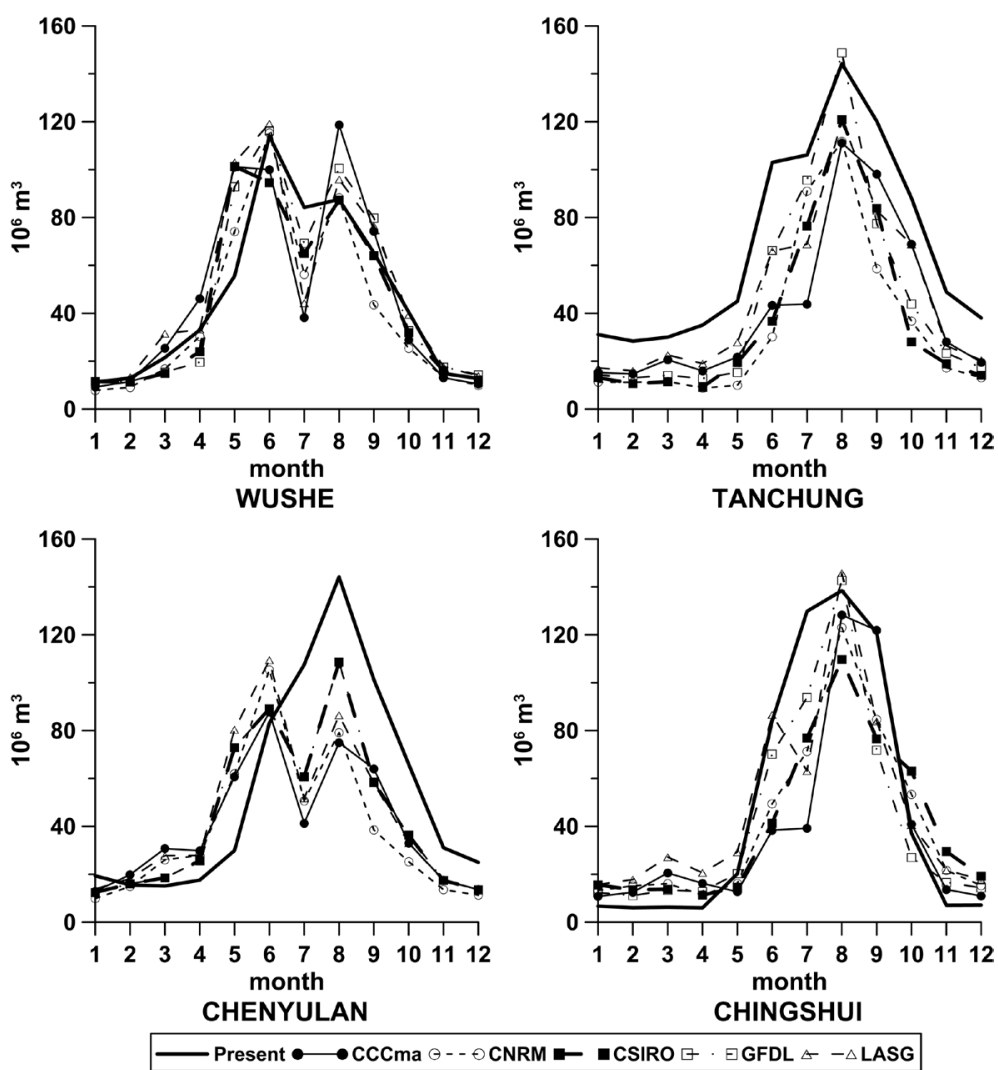

Fig. 11. Comparison of river flow of sub-basins between the present (2001 - 2010) and future (2046 - 2065).

\subsection{Impact of Climate Change on the Water Supply and Benefits of Hushan Reservoir}

In the following section, we assume that the industrial and domestic demands will remain the same in the present (2001 - 2010) and future (2046 - 2065). The daily industrial and domestic demands are $3.5 \times 10^{5}$ and $2.0 \times 10^{5} \mathrm{~m}^{3}$, respectively.

Although the Hushan Reservoir operational regulations are not yet stipulated, we assume that the Hushan Reservoir will be responsible for supplying all domestic demand because the Zhoshui River sediment concentration is always high. In addition, this reservoir must draw water from Chingshui Creek without affecting irrigation demand downstream.
Table 6 shows the water supply situation before and after building the Hushan Reservoir. The Hushan Reservoir clearly aids domestic supply. Future water shortages for irrigation and industry are exacerbated because of river flow reductions throughout the Zhoshui River basin (the decrement is $20.4 \%$ according to the weighted average; see section 4.3). On average, the annual irrigation and industry deficit increases by 159.2 and 4.5 million $\mathrm{m}^{3}$, maximum consecutive water-shortage days for irrigation and industry increase by 2 - 4 times, and the shortage index for industry is raised to 3.7 from 2.5. Moreover, the satisfaction and reliability temporal distributions indicate that water shortages from September to February in subsequent years will be more severe than those at present (Figs. 12 and 13).

Domestic demand could be fully satisfied when 
Table 6. Results of water supply simulation.

\begin{tabular}{|c|c|c|c|c|c|c|c|c|}
\hline & & \multirow{2}{*}{ Without Hushan in 2001 - 2010} & \multicolumn{6}{|c|}{ With Hushan in 2046 - 2065} \\
\hline & & & CCCma & CNRM & CSIRO & GFDL & LASG & Average \\
\hline \multirow{3}{*}{ Annual deficit $\left(10^{6} \mathrm{~m}^{3}\right)$} & Irr. & 456.4 & 548.0 & 803.1 & 651.0 & 478.1 & 597.4 & 615.6 \\
\hline & Ind. & 18.3 & 17.9 & 31.0 & 25.9 & 21.6 & 17.4 & 22.8 \\
\hline & Dom. & 11.2 & 0.0 & 0.0 & 0.0 & 0.0 & 0.0 & 0.0 \\
\hline \multirow{3}{*}{$\begin{array}{l}\text { Maximum consecutive } \\
\text { water-shortage days }\end{array}$} & Irr. & 57.0 & 117.0 & 166.0 & 116.0 & 87.0 & 105.0 & 118.2 \\
\hline & Ind. & 20.0 & 116.0 & 114.0 & 54.0 & 80.0 & 54.0 & 83.6 \\
\hline & Dom. & 63.0 & 0.0 & 0.0 & 0.0 & 0.0 & 0.0 & 0.0 \\
\hline \multirow{2}{*}{ Shortage index } & Ind. & 2.5 & 2.0 & 6.4 & 4.3 & 3.1 & 2.5 & 3.7 \\
\hline & Dom. & 4.1 & 0.0 & 0.0 & 0.0 & 0.0 & 0.0 & 0.0 \\
\hline
\end{tabular}

(a)

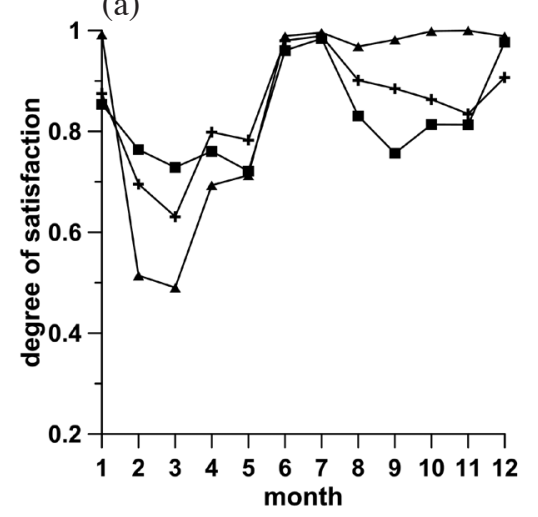

without Hushan reservoir in 2001 - 2010

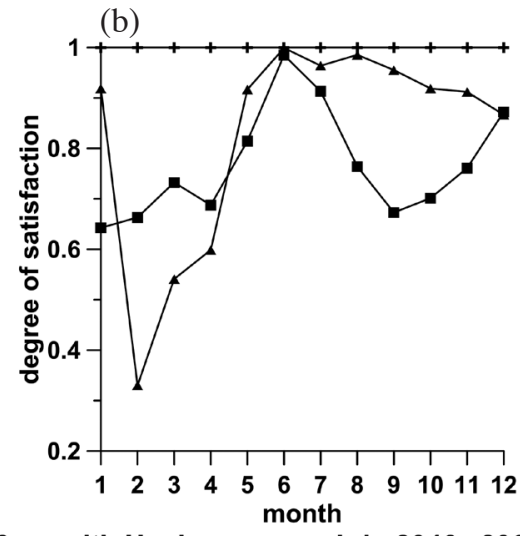

with Hushan reservoir in 2046 - 2065

(ensemble)

Fig. 12. Monthly Degree of Satisfaction: (a) without Hushan reservoir in the Present; (b) with Hushan reservoir in the future.

(a)

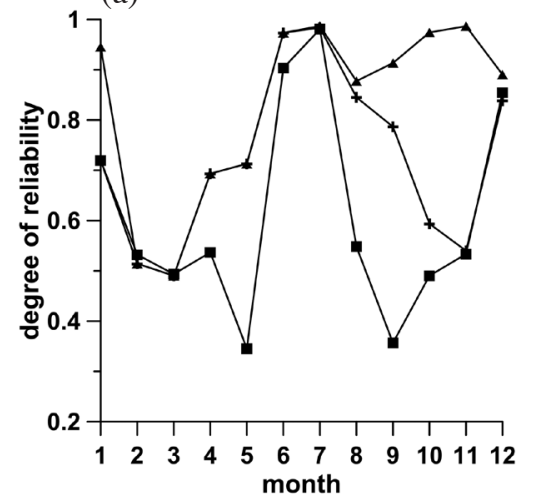

without Hushan reservoir in 2001 - 2010

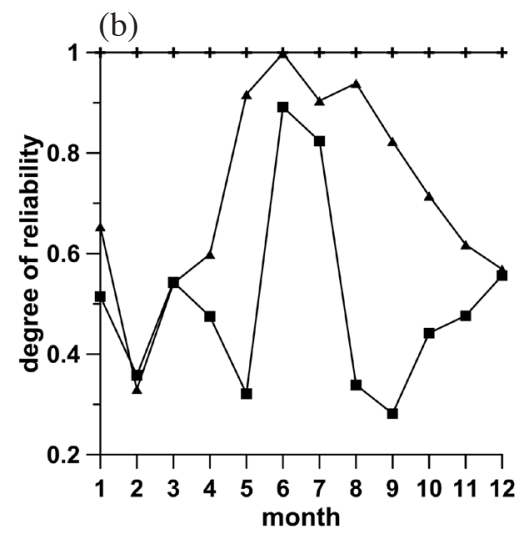

with Hushan reservoir in 2046 - 2065 (ensemble)

$\longrightarrow$ Irrigation $\longleftrightarrow$ Industrial $\longleftarrow$ Domestic

Fig. 13. Monthly Degree of Reliability: (a) without Hushan Reservoir in the Present; (b) withe Hushan reservoir in the future. 
the Hushan Reservoir begins operation (Table 6; Figs. 12 and 13). This result demonstrates that the new reservoir achieves its original objective to stabilize the domestic water supply. However, we found that Hushan Reservoir would release only 25.4 million $\mathrm{m}^{3}$ per year in the future. This annual release is approximately $50 \%$ of the reservoir's capacity (52 million $\mathrm{m}^{3}$ ). To enhance the Hushan Reservoir utilization efficiency, alternatives should be evaluated that assist other water users.

\subsection{Adaptations for Industrial and Irrigation Demands}

Because different GCMs produce different patterns of change in temperature and precipitation, multi-ensemble runs instead of single GCMs were used to reduce uncertainties. Therefore, the results show an average of all GCM simulations.

Compared with domestic demand, future irrigation and industrial demand will encounter higher pressures than at present. The first adaptation indicates that the Hushan Reservoir could significantly support industrial demand in the future without affecting domestic use. Comparing the industrial demand indices with the future average in Table 6 and case (a) in Table 7 , in which the annual shortage drops from $22.8-0.3$ million $\mathrm{m}^{3}$, indicates that maximum consecutive water-shortage days would decrease to 7.2 from 83.6 days, and the shortage index would decline to 0.02 . The temporal satisfaction degree distributions [part (b) in Fig. 12 vs. part (a) in Fig. 14] and reliability degree [part (b) in Fig. 13 vs. part (a) in Fig. 15] indicate that these industrial supply indices will be higher than $90 \%$ in the future. Consequently, the Hushan Reservoir utilization efficiency will increase after supporting industrial demand. The future annual Hushan Reservoir release increases to 47.7 million $\mathrm{m}^{3}$, compared to 25.4 million $\mathrm{m}^{3}$ per year at present.

Currently, the conveyance losses due to irrigation in the Changhua and Yunlin areas are 40.7 and 36.0\%, respectively. These values are higher than the average loss in Taiwan. The second adaptation further reduces the irrigation conveyance loss in both areas to an average of $30 \%$. Case (b) in Table 7, and Figs. 14 and 15 show the water supply simulations after reducing conveyance loss. By comparing cases (b) and (a), we find that the annual irrigation deficit decreases by 83.0 million $\mathrm{m}^{3}(13.5 \%)$. Additionally, the number of maximum consecutive water-shortage days decrease to 95.8 days from 118.2 days, and the satisfaction and reliability degree from September to December also improves. However, Alternative 2 is unable to return to the deficit level prior to the Hushan operation. The annual shortage at that time was approximately 456.4 million $\mathrm{m}^{3}$ per year [case (a), Table 6].

Crop rotation or fallow fields are options for saving water during shortages. According to the simulation results shown in Table 6 (in the case of without Hushan in 2001 2010) and Table 7 case (b), an extra 76.2 million $\mathrm{m}^{3}$ deficit occurs after improving irrigation conveyance loss. We considered applying area reduction as a possible alternative to offset future water deficits. Using trial and error, we found that reducing farming areas by $10 \%$ in the second paddy growth season would allow the annual irrigation deficit to return to the present level. According to case (c) in Table 7, the annual irrigation deficit would drop to 457.0 million $\mathrm{m}^{3}$ if the adaptations were applied. However, indices such as irrigation satisfaction and reliability [case (c), Figs. 14 and 15] would not return to the present level [case (a) in Figs. 12 and 13]. These indices are affected mainly by climate change.

\section{CONCLUSIONS}

The impact of climate change on water resources is of high concern. However, the limitations imposed by hydrological spatial and temporal variation conditions and the

Table 7. Results of water supply simulation of adaptations in 2046 - 2065.

\begin{tabular}{c|c|c|c|c}
\hline \multirow{2}{*}{ Indices of assessment } & \multirow{2}{*}{ Kinds of demand } & \multicolumn{3}{|c}{ Adaptations } \\
\cline { 3 - 5 } & & $(\mathbf{a})$ & $(\mathbf{b})$ & $(\mathbf{c})$ \\
\hline \multirow{2}{*}{ Annual deficit $\left(10^{6} \mathrm{~m}^{3}\right)$} & Irrigation & 615.6 & 532.6 & 457.0 \\
& Industrial & 0.3 & 0.2 & 0.2 \\
& Domestic & 0.0 & 0.0 & 0.0 \\
\hline \multirow{2}{*}{ Maximum consecutive water-shortage days } & Irrigation & 118.2 & 95.8 & 91.8 \\
& Industrial & 7.2 & 5.6 & 6.6 \\
& Domestic & 0.0 & 0.0 & 0.0 \\
\hline \multirow{2}{*}{ Shortage index } & Industrial & 0.02 & 0.01 & 0.01 \\
& Domestic & 0.0 & 0.0 & 0.0 \\
\hline
\end{tabular}

Note: (a) Hushan supports industrial demand; (b) Hushan supports industrial demand and conveyance loss of irrigation reduces to $30 \%$; (c) further reduces $10 \%$ of irrigation area in second cropping season. 


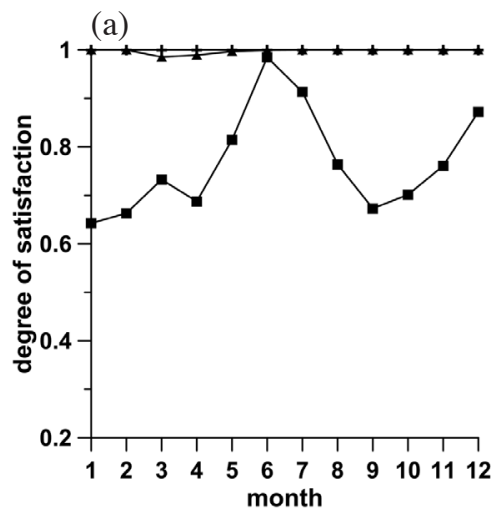

Hushan supports industrial demand (b)

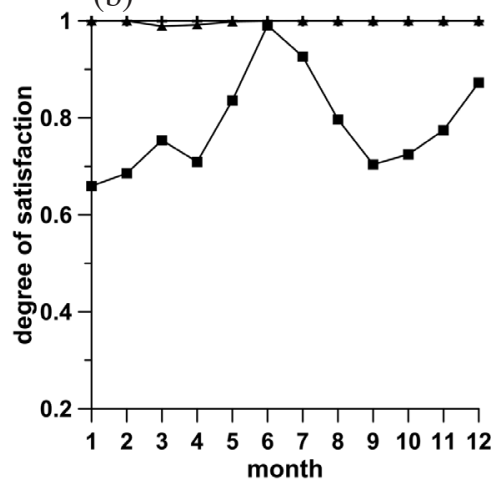

further reduce the conveyance loss of irrigation to $30 \%$

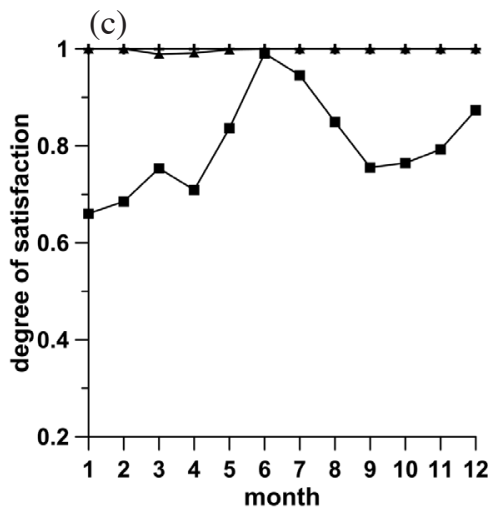

further reduce $10 \%$ of irrigation area in second cropping season

\footnotetext{
$\rightarrow$ Irrigation $\longleftrightarrow$ Industrial + Domestic
}

Fig. 14. Degree of satisfaction for adaptations in 2046 - 2065: (a) if Hushan supports industrial demand; (b) if further reduce the conveyance loss of irrigation to $30 \%$; (c) if further reduce $10 \%$ of irrigation area in second cropping season.

(a)

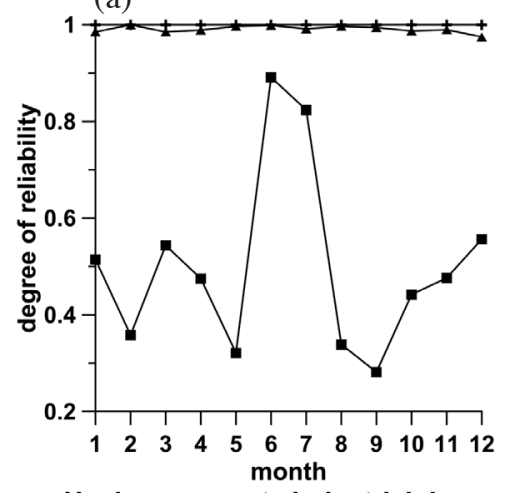

Hushan supports industrial demand (b)

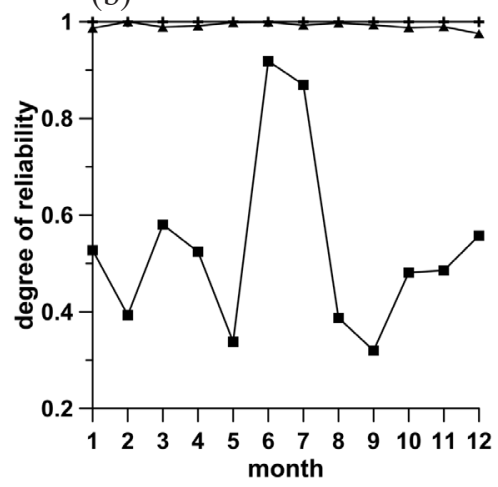

further reduce the conveyance loss of irrigation to $30 \%$ (c)

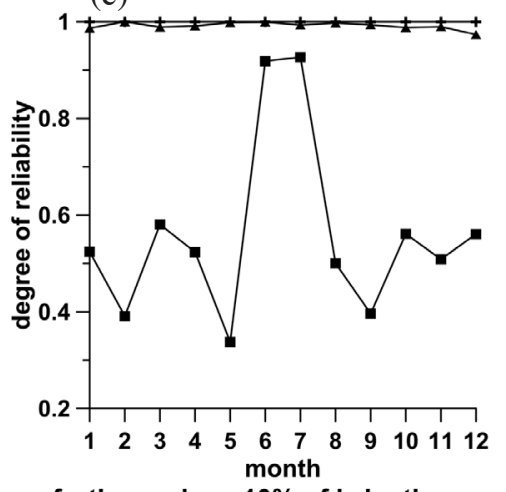

further reduce $10 \%$ of irrigation area in second cropping season

Fig. 15. Degree of reliability for adaptations in 2046 - 2065: (a) if Hushan supports industrial demand; (b) if further reduce the conveyance loss of irrigation to $30 \%$; (c) if further reduce $10 \%$ of irrigation area in second cropping season.

complexity of human intervention effects in the environment hinder estimation (Rees et al. 1997). This study investigated the impact of climate change on water resources within the period 2046 - 2065. The Zhoshui River basin in Central Taiwan was selected for analysis.

This paper demonstrates an integrated procedure for assessing water resources system response to climate change on the basin scale, and provides a reference for people concerned with local scale planning practices related to the impact of climate change. Bias correction was attained using a quadrant transformation method. A two-layer tank model was used for rainfall-runoff estimation. A water balance model for paddy fields was proposed for simulating irrigation water requirements. The applicability of these models was demonstrated in this study.

Comparison of the projections from 2001 - 2010 and
2046 - 2065 suggests that future irrigation water requirements will increase $10 \%$ less in each cropping season in the Changhua and Yunlin areas. However, future river flow in the Zhoshui basin will decrease by approximately $20 \%$. Consequently, water shortage is inevitable, particularly from September to February, owing to irrigation. Thus, climate change will have a considerable impact on water supply, particularly in the agricultural sector. The annual deficit associated with irrigation and industrial demand may increase by $30 \%$ compared to the present levels, and the maximum number of consecutive water-shortage days will nearly double.

Adaptations were introduced to alleviate the impacts of climate change on water resources. Domestic demand will be fully met after the Hushan Reservoir comes on-line in mid-2016. Furthermore, the industrial water shortage can be 
substantially reduced without affecting domestic demand if the Hushan Reservoir can support it.

Alternatively, reducing irrigation conveyance losses and farming areas are effective ways to mitigate water shortages for irrigation in the future. We recommend reducing conveyance loss by $30 \%$ and cutting farming areas by $10 \%$ in the second paddy growth season to mitigate future annual irrigation deficits and retain deficits at the present level.

Acknowledgements The authors thank the National Taiwan University Global Change Center for providing relevant meteorological projections. This study was sponsored by the Ministry of Science and Technology, Taiwan in 2012 - 2014 (NSC 101-2625-M-019-003, MOST 102-2625-M019-001, and MOST 103-2625-M-019-001).

\section{REFERENCES}

Allen, R. G., L. S. Pereira, D. Raes, and M. Smith, 2006: Crop Evapotranspiration - Guidelines for Computing Crop Water Requirements - FAO Irrigation and Drainage Paper 56, FAO - Food and Agriculture Organization of the United Nations, Rome.

Chen, R. S., L. C. Pi, and C. C. Hsieh, 2005: Application of parameter optimization method for calibrating tank model. J. Am. Water Resour. Assoc., 41, 389-402, doi: 10.1111/j.1752-1688.2005.tb03743.x. [Link]

Eskridge, K. M. and E. J. Stevens, 1987: Growth curve analysis of temperature-dependent phenology models. Agron. J., 79, 291-297, doi: 10.2134/agronj1987.0002 $1962007900020023 x$. [Link]

Gilmore, E. C. and J. S. Rogers, 1958: Heat units as a method of measuring maturity in corn. Agron. J., 50, 611615, doi: 10.2134/agronj1958.0002196200500010001 4x. [Link]

Hardke, J., C. E. Wilson, Jr., and R. Norman, 2013: DD50 computerized rice management program. In: Hardke, J. T. (Ed.), Arkansas Rice Projection Handbook - MP192, University of Arkansas Cooperative Extension Service Print Media Center, Little Rock, Arkansas, U.S.A., 4551.

Hodges, T., 1991: Temperature and water stress effects on phenology. In: Hodges, T. (Ed.), Predicting Crop Phenology, CRC Press, Florida, U.S.A., 8-9.

Hsu, H. H., C. Chou, Y. Wu, M. M. Lu, C. T. Chen, and Y. M. Chen, 2011: Climate Change in Taiwan: Scientific Report 2011 (Summary), National Science Council, Taipei, Taiwan.

Hualien District Agricultural Research and Extension Station, 2006: Annual Report, Hualien District Agricultural Research and Extension Station, Council of Agriculture, Executive Yuan, Taiwan. (in Chinese)

Hualien District Agricultural Research and Extension Station, 2007: Annual Report, Hualien District Agricul- tural Research and Extension Station, Council of Agriculture, Executive Yuan, Taiwan. (in Chinese)

Huang, W. C., Y. Chiang, R. Y. Wu, J. L. Lee, and S. H. Lin, 2012: The Impact of Climate Change on Rainfall Frequency in Taiwan. Terr. Atmos. Ocean. Sci., 23, 553-564, doi: 10.3319/TAO.2012.05.03.04(WMH). [Link]

Huang, W. C., Y. H. Wu, and J.L. Lee, 2014a: Impact of climate change on rainfall in Taiwan during 2046-2065. J. Taiwan Agric. Eng., 60, 66-80. (in Chinese)

Huang, W. C., T. Y. Chu, and J. L. Lee, 2014b: Impact on water supply under climate change for Shihmen Reservoir. The 13th Conference of International Society of Paddy and Water Environment Engineering, Kaohsiung, Taiwan.

Hung, W.C., C. Hwang, J.C.Liou, Y.S. Lin, and H. L. Yang, 2012: Modeling aquifer-system compaction and predicting land subsidence in central Taiwan. Eng. Geol., 147-148, 78-90, doi: 10.1016/j.enggeo.2012.07.018. [Link]

IPCC, 2007: Climate Change 2007: Synthesis Report. In: Core Writing Team, R. K. Pachauri, and A. Reisinger (Eds.), Contribution of Working Groups I, II and III to the Fourth Assessment Report of the Intergovernmental Panel on Climate Change, IPCC, Geneva, Switzerland.

Kalnay, E., M. Kanamitsu, R. Kistler, W. Collins, D. Deaven, L. Gandin, M. Iredell, S. Saha, G. White, J. Woollen, Y. Zhu, M. Chelliah, W. Ebisuzaki, W. Higgins, J. Janowiak, K. C. Mo, C. Ropelewski, J. Wang, A. Leetmaa, R. Reynolds, R. Jenne, and D. Joseph, 1996: The NCEP/NCAR 40-year reanalysis project. Bull. Amer. Meteorol. Soc., 77, 437-471, doi: 10.1175/1520-0477( 1996)077<0437:TNYRP>2.0.CO;2. [Link]

Kan, C. E., 2002: Study on the Effective Use Strategies of Agricultural Conserved Water, Water Resources Agency, Ministry of Economic Affairs, Taiwan.

Lee, J. L. and W. C. Huang, 2014: Impact of climate change on the irrigation water requirement in northern Taiwan. Water, 6, 3339-3361, doi: 10.3390/w6113339. [Link]

Lee, K. T., 1993: Tank Model and Rainfall-Runoff Simulation. J. Taiwan Agric. Eng., 39, 20-28. (in Chinese)

Lin, S. H., Y. C. Chen, W. S. Lin, and C. M. Liu, 2009: Climate change projection for Taiwan based on statistical downscaling on daily temperature and precipitation. The 15th International Joint Seminar on the Regional Deposition Processes in the Atmosphere and Climate Change, Taipei, Taiwan.

Lin, S. H., C. M. Liu, W. C. Huang, S. S. Lin, T. H. Yen, H. R. Wang, J. T. Kuo, and Y. C. Lee, 2010: Developing a yearly warning index to assess the climatic impact on the water resources of Taiwan, a complexterrain island. J. Hydrol., 390, 13-22, doi: 10.1016/j. jhydrol.2010.06.024. [Link] 
Miller, P., W. Lanier, and S. Brandt, 2001: Using Growing Degree Days to Predict Plant Stages, Montana State University Extension Service, Montana, U.S.A.

Nakicenovic, N. and R. Swart, 2000: Special Report on Emissions Scenarios, Cambridge Univ. Press, U.K.

Powell, M. J. D., 1964: An efficient method for finding the minimum of a function of several variables without calculating derivatives. Comput. J., 7, 155-162, doi: 10.1093/comjnl/7.2.155. [Link]

Rees, H. G., K. M. Croker, N. S. Reynard, and A. Gustard, 1997: Estimation of renewable water resources in the European Union. FRIEND'97-Regional Hydrology: Concepts and Models for Sustainable Water Resource Management, Proceedings of the Postojna, Slovenia, Conference, IAHS Publ., no. 246, 31-38.

Russelle, M. P., W. W. Wilhelm, R. A. Olson, and J. F. Power, 1984: Growth analysis based on degree days. Crop Sci., 24, 28-32, doi: 10.2135/cropsci1984.00111 83X002400010007x. [Link]

Searcy, J. K., 1959: Flow-duration curves. Manual of Hydrology: Part 2, Low-Flow Techniques, United States Department of the Interior, Washington, U.S.A.

Shaw, S. B. and S. J. Riha, 2011: Assessing temperaturebased $P E T$ equations under a changing climate in temperate, deciduous forests. Hydrol. Process., 25, 1466-
1478, doi: 10.1002/hyp.7913. [Link]

Shih, C. C. C., Y. P. Hsu, Y. S. Cao, and C. E. Kan, 1996: Principles of Irrigation and Drainage, Central Book Publishing, Taipei, Taiwan, 227. (in Chinese)

Sugawara, M., 1961: On the analysis of runoff structure about several Japanese rivers. Jpn. J. Geophys., 2, 1-76.

Tanakamaru, H., 1995: Parameter estimation for the tank model using global optimization. Trans. JSIDRE, 178, 103-112, doi: 10.11408/jsidre1965.1995.503. [Link]

The University of Adelaide, Flinders University, and The University of Waikato, 2009: Identifying hot spots of climate change impact. Climate Change and Migration in Asia and the Pacific, Asian Development Bank, Mandaluyong City, Philippines, 15-18.

Tung, H. and J. C. Hu, 2012: Assessments of Serious Anthropogenic land subsidence in Yunlin County of central Taiwan from 1996 to 1999 by Persistent Scatterers InSAR. Tectonophysics, 578, 126-135, doi: 10.1016/j. tecto.2012.08.009. [Link]

Yokoo, Y. and S. Kazama, 2012: Numerical investigations on the relationships between watershed characteristics and water balance model parameters: Searching for universal relationships among regional relationships. Hydrol. Process., 26, 843-854, doi: 10.1002/hyp.8299. [Link] 